\title{
Pengaruh Substitusi Sebagian Agregat Halus Dengan Abu Batu Dan Penambahan Fly Ash Terhadap Kuat Tekan Beton
}

\author{
Heronimus Lumenta ${ }^{1}$, Stefanus Tri Bintoro ${ }^{2}$, Ir.David Widianto, MT $^{3}$, Ir. Widija Suseno, MT. ${ }^{4}$ \\ e-mail: herolumen@gmail.com ${ }^{1}$, stefanusbintoro@yahoo.com ${ }^{2}$
}

Universitas Katolik Soegijapranata; Jalan Pawiyatan Luhur IV/1, Semarang

\begin{abstract}
The purpose of this research is to determine concrete compressive strengths with screenings variation of $0 \%, 25 \%, 50 \%$, and $75 \%$ by addition the weight of fine aggregate (sand) and fly ash $15 \%$ by the weight of cement. The background of this research is increasing demand for concrete and the limited availability of concrete substances. Therefore innovation is needed to maintain the availability of concrete constituent materials and also to improve the quality of concrete. $U p$ until now a lot of researches have been carried out regarding of substitute materials or added materials that can be substituted in making concrete.
\end{abstract}

Based on this background the writer chose one of the added ingredients that can improve the quality (compressive strength) of concrete, namely fly ash. Fly ash produced from the remaining combustion of coal in the Steam Power Plant (PLTU). While for substitution materials, the writer used the screenings that substituted by sand. In this study the writer used four variations of concrete with a ratio of $0 \%$ screenings : $100 \%$ sand, $25 \%$ screenings : $75 \%$ sand, $50 \%$ screenings : $50 \%$ sand, $75 \%$ screenings: $25 \%$ sand. Every variant was added with fly ash as much as $15 \%$ of the weight of cement.

The result of this research was indicated that variations $25 \%$ screenings, $75 \%$ sand plus fly ash of the weight of cement that having the highest quality of concrete among the other variations were as much as 298,95 kg/ $\mathrm{cm}^{2}$ at the age of 7 days; $403,23 \mathrm{~kg} / \mathrm{cm}^{2}$ at the age of 28 days; and $456,53 \mathrm{~kg} / \mathrm{cm}^{2}$ at the age of 42 days. This was because means of air vents was in concrete filled by granules of screening so that the concrete became denser and made concrete strong press was increased.

Keywords: compressive strength, screenings, fly ash, added material, substitution, concrete.

\section{PENDAHULUAN}

\subsection{Latar Belakang Masalah}

Perkembangan infrastruktur dari tahun ke tahun semakin bertambah dengan cepat. Seiring dengan hal tersebut kebutuhan beton juga semakin meningkat. Beton merupakan bagian yang sangat penting dalam bidang konstruksi. Dengan meningkatnya kebutuhan beton, bahan penyusun beton juga meningkat. Bahan penyusun beton pada umumnya yaitu agregat kasar (kerikil), agregat halus (pasir), semen, dan air.
Dalam penelitian ini digunakan abu batu sebagai bahan substitusi dengan agregat halus dengan variasi abu batu $0 \%$, $25 \%, 50 \%$, dan $75 \%$ dari berat pasir ditambah dengan fly ash sebanyak $15 \%$ dari berat semen.

Tujuan dari penelitian ini adalah mengetahui nilai kuat tekan beton dengan variasi abu batu $0 \%, 25 \%, 50 \%$, dan $75 \%$ dari berat agregat halus (pasir) dengan ditambah fly ash 15\% dari berat semen, mengetahui pengaruh substitusi sebagian agregat halus dengan abu batu dengan variasi abu batu $0 \%$ : pasir $100 \%$; abu 
batu 25\% : pasir 75\%; abu batu 50\% : pasir 50\%; abu batu 75\% : pasir 25\% (tiap varian ditambah dengan fly ash sebanyak $15 \%$ dari berat semen) pada umur 7 hari, 28 hari, dan 42 hari, mengetahui efisiensi penggunaan agregat halus (pasir) dengan perbandingan berat abu batu terhadap pasir yaitu abu batu $0 \%$ : pasir 100\%; abu batu $25 \%$ : pasir $75 \%$; abu batu $50 \%$ : pasir 50\%; abu batu $75 \%$ : pasir $25 \%$. Tiap varian ditambah dengan fly ash sebanyak $15 \%$ dari berat semen.

\subsection{Tujuan Penelitian}

Tujuan dari penelitian ini adalah sebagai berikut :

a) Mengetahui nilai kuat tekan beton dengan variasi abu batu $0 \%, 25 \%$, $50 \%$, dan $75 \%$ dari berat agregat halus (pasir) dengan ditambah fly ash $15 \%$ dari berat semen.

b) Mengetahui pengaruh substitusi sebagian agregat halus dengan abu batu dengan variasi abu batu $0 \%$ : pasir 100\%; abu batu $25 \%$ : pasir $75 \%$; abu batu $50 \%$ : pasir $50 \%$; abu batu $75 \%$ : pasir $25 \%$ (tiap varian ditambah dengan fly ash sebanyak $15 \%$ dari berat semen) pada umur 7 hari, 28 hari, dan 42 hari.

c) Mengetahui efisiensi penggunaan agregat halus (pasir) dengan perbandingan berat abu batu terhadap pasir yaitu abu batu $0 \%$ : pasir $100 \%$; abu batu 25\% : pasir 75\%; abu batu $50 \%$ : pasir 50\%; abu batu $75 \%$ : pasir $25 \%$. Tiap varian ditambah dengan fly ash sebanyak $15 \%$ dari berat semen.

\subsection{Manfaat Penelitian}

Melalui penelitian ini diharapkan dapat memberikan informasi nilai kuat tekan beton dan efisiensi penggunaan agregat halus (pasir) dengan perbandingan berat abu batu terhadap pasir yaitu abu batu $0 \%$ : pasir $100 \%$; abu batu $25 \%$ : pasir $75 \%$; abu batu $50 \%$ : pasir 50\%; abu batu $75 \%$ : pasir $25 \%$. Tiap varian ditambah dengan fly ash sebanyak $15 \%$ dari berat semen.

\subsection{Pembatasan Masalah}

Agar penelitian ini tidak menyimpang dari topik maka penulis perlu membatasi penelitian sebagai berikut.

a) Kuat tekan beton $\mathrm{K} 375\left(f_{c^{\prime}}{ }^{\prime}=31,125\right.$ $\mathrm{MPa}$ ).

b) Abu batu yang digunakan merupakan hasil sampingan batu pecah Seloarto, Kabupaten Semarang. Abu batu yang digunakan lolos uji saringan No.16 $(1,18 \mathrm{~mm})$ dan tertahan No.50 $(0,300$ $\mathrm{mm})$.

c) Perbandingan berat abu batu terhadap pasir yaitu abu batu $0 \%$ : pasir $100 \%$; abu batu 25\% : pasir 75\%; abu batu $50 \%$ : pasir $50 \%$; abu batu $75 \%$ : pasir $25 \%$. Tiap varian ditambah dengan fly ash sebanyak $15 \%$ dari berat semen.

d) Fly ash yang digunakan sebagai bahan tambah berasal dari PLTU Tanjung Jati Jepara yaitu fly ash kelas C.

e) Masing-masing variasi terdiri dari 9 benda uji silinder berdiameter $15 \mathrm{~cm}$ dan tinggi $30 \mathrm{~cm} .3$ benda uji untuk pengujian pada umur 7 hari, 3 benda uji berikutnya untuk pengujian pada umur 28 hari, dan 3 benda uji lagi untuk pengujian pada umur 42 hari. Jumlah total benda uji silinder sebanyak 36 buah.

f) Pasir yang digunakan merupakan pasir Muntilan yang berasal dari Kecamatan Dukun, Kabupaten Magelang.

g) Batu pecah yang digunakan berasal dari Seloarto, Kabupaten Semarang.

h) Nilai slump test yang digunakan $10 \mathrm{~cm}$ $\pm 2 \mathrm{~cm}$.

i) Semen yang digunakan adalah semen portland Holcim tipe I (Ordinary Portland Cement).

\section{TINJAUAN UMUM}

\subsection{Beton}


Menurut SNI 03-2847-2002, beton adalah campuran antara semen portland atau semen hidraulik yang lain, agregat halus, agregat kasar dan air, dengan atau tanpa bahan tambahan yang membentuk masa padat. Dalam bidang teknik sipil, beton merupakan salah satu bahan konstruksi yang sering digunakan pada jembatan, gedung, jalan, dan lain-lain.

\subsection{Bahan Penyusun Beton}

Beton tersusun dari empat bahan utama, yaitu agregat kasar, agregat halus, semen, dan air. Dari keempat bahan penyusun utama beton tersebut dapat ditambah dengan bahan tambah yang dapat meningkatkan mutu beton. Selain bahan tambah dari keempat bahan penyusun utama beton juga dapat disubstitusikan dengan bahan lain yang juga dapat meningkatkan mutu beton. Berikut ini adalah pengertian dari keempat bahan penyusun utama beton, ditambah fly ash sebagai bahan tambah, dan abu batu sebagai bahan substitusi agregrat halus.

\subsubsection{Agregat Halus}

Agregat halus merupakan pasir alam sebagai hasil disintegrasi "alami" dari batuan atau pasir yang dihasilkan oleh industri pemecah batu dan mempunyai ukuran butir terbesar 4,75 mm (No. 4). (SNI 1969:2008). Menurut SNI 03-6820-2002, syarat agregat halus dalam plesteran dan adukan harus sebagai bahan pengisi, penahan penyusutan, penambah kekuatan. Agregat halus yang digunakan tidak boleh mengandung zat organik dan kadar lumpur pada agregat halus maksimum 5\%.

\subsubsection{Agregat kasar}

Agregat kasar merupakan kerikil sebagai hasil disintegrasi "alami" dari batuan atau berupa batu pecah yang diperoleh dari industri pemecah batu dan mempunyai ukuran butir antara $4,75 \mathrm{~mm}$ (No. 4) sampai $40 \mathrm{~mm}$ (No. 1,5 inci). (SNI 1969:2008). Menurut SNI 03-28472002 ukuran maksimum nominal agregat kasar harus tidak melebihi $1 / 5$ jarak terkecil antara sisi-sisi cetakan, 1/3 ketebalan pelat lantai, $3 / 4$ jarak bersih minimum antara tulangan-tulangan atau kawat-kawat, bundle tulangan, atau tendon-tendon prategang atau selongsong-selongsong.

\subsubsection{Semen portland}

Semen portland adalah semen hidrolis yang dihasilkan dengan cara menggiling terak semen portland terutama yang terdiri atas kalsium silikat yang bersifat hidrolis dan digiling bersama-sama dengan bahan tambahan berupa suatu atau lebih bentuk kristal senyawa kalsium sulfat dan boleh ditambah dengan bahan tambahan lain. (SNI 15-2049-2004).

\subsubsection{Perkembangan Penelitian Fly Ash \\ Dari penelitian Wikana (2014)} mengungkapkan bahwa nilai kuat tekan beton semakin meningkat sejalan dengan bertambahnya prosentase fly ash mulai dari $0 \%$ sampai $22,5 \%$ dari berat semen dan abu batu $12,5 \%$ dari berat agregat halus (pasir), adapun penggantian semen dengan fly ash di atas 22,5\% kuat tekan beton mengalami penurunan. Peningkatan kuat tekan beton disebabkan oleh pemakaian fly ash dan abu batu sebagai penggantian sebagian semen yang mampu mengisi rongga yang ada di dalam beton sehingga menjadi lebih padat dan dapat meningkatkan sifat mekanik beton tersebut. Pemakaian kadar fly ash yang terlalu tinggi, tidak menambah kekuatan tekan benda uji. Hal ini disebabkan karena kelebihan kebutuhan bahan pengisi pori.

\section{METODE PENELITIAN}

Ada tiga tahap dalam penelitian ini, dimulai dari Tahap I yang berisi tentang persiapan penelitian, Tahap II yang berisi tentang pelaksanaan penelitian, dan yang terakhir yaitu Tahap III yang berisi 
tentang kesimpulan dan saran dari penelitian.

\subsubsection{Pengadaan Material}

Material yang digunakan untuk penelitian adalah agregat kasar berasal dari Seloarto, Kab. Semarang, agregat halus dari Kec. Dukun, Kab. Magelang, semen Holcim tipe OPC, air, dan abu batu berasal dari hasil sampingan batu pecah Seloarto, Kab. Semarang. Bahan tambah yang digunakan yaitu fly ash tipe $\mathrm{C}$ yang berasal dari PLTU Tanjung Jati Jepara.

\subsubsection{Pengujian Material}

Pengujian material wajib dilakukan sebelum material-material tersebut digunakan untuk campuran dalam pembuatan beton. Pengujian material dilakukan di Laboratorium CV. Jati Kencana Beton dan Laboratorium Teknik Sipil Universitas Katolik Soegijapranata.

\subsubsection{Pembuatan Benda Uji}

Pembuatan benda uji pada penelitian ini yaitu silinder dengan diameter $15 \mathrm{~cm}$ dan tinggi $30 \mathrm{~cm}$. Pembuatan benda uji pada penelitian ini berjumlah 36 buah silinder dengan diameter $15 \mathrm{~cm}$ dan tinggi $30 \mathrm{~cm}$. Masing-masing variasi terdiri dari 9 benda uji. 3 benda uji untuk pengujian pada umur 7 hari, 3 benda uji berikutnya untuk pengujian pada umur 28 hari, dan 3 benda uji lagi untuk pengujian pada umur 42 hari.

\subsubsection{Perencanaan Mix Design}

Setelah pengujian material
dilakukan dan material tersebut
memenuhi syarat dan ketentuan, tahap
selanjutnya yaitu perencanaan mix
design. Penelitian ini menggunakan
perencanaan mix design metode SNI
7656:2012.

\subsubsection{Pembuatan Benda Uji}

Pembuatan benda uji pada penelitian ini yaitu silinder dengan diameter $15 \mathrm{~cm}$ dan tinggi $30 \mathrm{~cm}$. Berikut merupakan langkah-langkah pembuatan benda uji dengan concrete mixer. a) Agregat kasar, agregat halus, semen, abu batu, dan fly ash yang sudah ditimbang sesuai dengan perencanaan dimasukkan ke dalam concrete mixer.

b) Lalu concrete mixer diputar agar tercampur dengan baik.

c) Memasukkan air sesuai dengan perencanaan ke dalam concrete mixer.

d) Setelah tercampur secara merata, masukkan superplasticizer. Tahap selanjutnya yaitu melakukan slump test. Dalam penelitian ini nilai slump test yang digunakan adalah $10 \mathrm{~cm} \pm 2$ $\mathrm{cm}$.

e) Apabila nilai slump test sudah sesuai dengan perencanaan kemudian adukan beton tersebut dimasukkan ke dalam benda uji silinder.

f) Benda uji yang masih berada di dalam cetakan kemudian diletakkan di tempat yang tidak terkena matahari.

g) Membuka cetakan setelah $1 \times 24$ jam dari pembuatan benda uji.

Pembuatan benda uji pada penelitian ini berjumlah 36 buah silinder dengan diameter $15 \mathrm{~cm}$ dan tinggi $30 \mathrm{~cm}$. Masing-masing variasi terdiri dari 9 benda uji. 3 benda uji untuk pengujian pada umur 7 hari, 3 benda uji berikutnya untuk pengujian pada umur 28 hari, dan 3 benda uji lagi untuk pengujian pada umur 42 hari.

\subsubsection{Perawatan Benda Uji}

Perawatan benda uji dilakukan setelah cetakan dibuka. Benda uji diberi tanda atau tulisan agar mudah dibedakan. Proses perawatan benda uji dalam penelitian ini dengan cara direndam dalam bak perendaman hingga benda uji berumur 7 hari, 28 hari, dan 42 hari.

\subsubsection{Pengujian Benda $\mathbf{U j i}$}

Pengujian benda uji yang dilakukan pada penelitian ini yaitu pengujian kuat tekan beton. Pengujian dilakukan saat beton berumur 7 hari, 28 hari, dan 42 hari. Uji kuat tekan beton pada penelitian ini menggunakan alat compression test. Uji 
kuat tekan beton dilakukan di Laboratorium CV. Jati Kencana Beton.

\subsubsection{Analisis Data}

Analisis data dilakukan dengan cara membandingkan nilai kuat tekan yang didapat dari pengujian dengan kuat tekan rencana.
4. ANALISIS DAN PEMBAHASAN 4.1. Hasil Pengujian Material

Pengujian material dilakukan sebelum mix design dilakukan. Uji material yang dilakukan meliputi agregat kasar, agregat halus (pasir), abu batu, dan semen. Tabel 4.1 merupakan hasil pengujian material agregat halus.

Tabel 4.1 Hasil Uji Material Agregat Halus

\begin{tabular}{|l|c|c|c|c|}
\hline \multirow{2}{*}{ Jenis Pengujian } & \multicolumn{2}{|c|}{ Hasil Pengujian } & \multirow{2}{*}{ Standar } & \multirow{2}{*}{ Kesimpulan } \\
\cline { 2 - 3 } & Pasir Muntilan & Abu Batu & & \\
\hline Kandungan zat organik & Kuning muda & Bening & $0-10 \%$ & Memenuhi syarat \\
\hline Kandungan lumpur & $18,18 \%$ & $23,33 \%$ & Max $5 \%$ & Tidak memenuhi syarat \\
\hline Bulk specific gravity SSD & $2,625 \mathrm{gr} / \mathrm{cm}^{3}$ & $2,681 \mathrm{gr} / \mathrm{cm}^{3}$ & $2,5-2,7 \mathrm{gr} / \mathrm{cm}^{3}$ & Memenuhi syarat \\
\hline Absorbtion & $0,44 \%$ & $0,50 \%$ & - & - \\
\hline Modulus halus & 3,26 & 2,99 & $1,5-3,8$ & Memenuhi syarat \\
\hline
\end{tabular}

Pengujian material yang dilakukan pada agregat halus sebagian memenuhi standar yang berlaku. Kandungan lumpur yang ada di dalam agregat halus terlalu banyak sehingga harus dicuci terlebih dahulu.

Tabel 4.2 merupakan hasil pengujian material agregat kasar.

Tabel 4.2 Hasil Uji Material Agregat Kasar

\begin{tabular}{|l|c|c|c|}
\hline \multicolumn{1}{|c|}{ Jenis Pengujian } & Hasil Pengujian & Standar & Kesimpulan \\
\hline Bulk specific gravity SSD & $2,690 \mathrm{gr} / \mathrm{cm}^{3}$ & $2,5-2,7 \mathrm{gr} / \mathrm{cm}^{3}$ & Memenuhi syarat \\
\hline Absorbtion & $1,18 \%$ & - & - \\
\hline Los Angeles Abration & $29,35 \%$ & $<40 \%$ & Memenuhi syarat \\
\hline
\end{tabular}

Pengujian material yang dilakukan pada agregat kasar memenuhi standar yang berlaku, sehingga sangat baik untuk digunakan dalam campuran beton.

\subsection{Hasil Uji Kuat Tekan Beton}

Berdasarkan hasil keseluruhan dari uji pengaruh substitusi agregat halus dengan abu batu ditambah dengan fly ash, maka didapatkan hasil grafik pada Gambar 4.1.

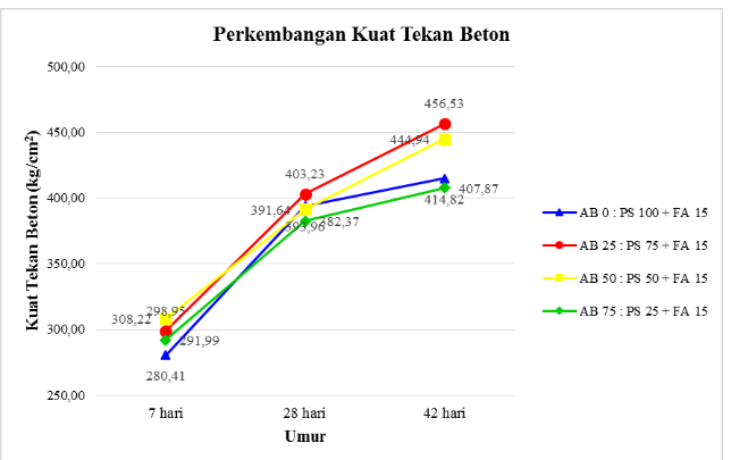

Gambar 4.1 Grafik Perkembangan Kuat Tekan Beton
Berdasarkan Gambar 4.1 dapat diketahui bahwa penggunaan agregat halus (pasir) yang efisien yaitu dengan perbandingan abu batu $25 \%$ : pasir $75 \%+$ fly ash $15 \%$ dari berat semen, disebabkan nilai kuat tekannya yang stabil sehinga baik digunakan. Hal ini disebabkan poripori yang ada di dalam beton terisi oleh abu batu, sehingga beton semakin rapat dan kuat tekan yang dihasilkan tinggi. Penggunaan abu batu yang berlebih akan mempengaruhi kuat tekan beton. Pasta semen yang seharusnya dapat menyelimuti dan merekatkan antar agregat tidak berfungsi dengan baik karena penggunaan abu batu yang terlalu banyak.

5. KESIMPULAN DAN SARAN 


\subsection{Kesimpulan}

Berdasarkan hasil penelitian yang telah dilakukan, maka dapat ditarik kesimpulan sebagai berikut:

a) Kuat tekan benda uji pada umur 42 hari masih mengalami peningkatan rata-rata sebesar $9,73 \%$ dari kuat tekan pada umur 28 hari.

b) Penggunaan agregat halus (pasir) yang efisien yaitu dengan perbandingan abu batu $25 \%$ : pasir $75 \%$ + fly ash $15 \%$ dari berat semen, disebabkan nilai kuat tekannya yang stabil sehinga baik digunakan.

c) Kuat tekan beton mengalami penurunan pada variasi abu batu $50 \%$ : pasir $50 \%+$ fly ash $15 \%$ dari berat semen dan variasi abu batu $75 \%$ : pasir $25 \%+$ fly ash $15 \%$ dari berat semen. Hal ini disebabkan butiran agregat abu batu yang seharusnya berfungsi sebagai filler terlalu banyak, sehingga pasta semen tidak dapat menyelimuti dan merekatkan seluruh agregat. Faktor ini yang mempengaruhi kuat beton menjadi turun.

\subsection{Saran}

Dari penelitian yang dilakukan penulis, maka penulis menyarankan dengan menggunakan perbandingan abu batu $25 \%$ : pasir $75 \%$ + fly ash $15 \%$ dari berat semen. Penambahan fly ash $15 \%$ dari berat semen dan substitusi abu batu sebesar $25 \%$ dari berat pasir menghasilkan mutu beton yang tinggi dan stabil. Penambahan fly ash dan substitusi abu batu memperkecil pori-pori yang ada dalam beton sehingga menghasilkan mutu beton yang tinggi.

Pada penelitian ini masih banyak yang harus diperbaiki untuk penelitian berikutnya, dengan demikian penulis memberikan saran sebagai berikut :

a) Agar dapat menghasilkan kuat tekan yang lebih optimum sebaiknya penggunaan abu batu sebagai bahan substitusi pasir berkisar pada perbandingan abu batu 25\% : pasir $75 \%+$ fly ash $15 \%$.

b) Material yang digunakan dalam pembuatan benda uji adalah material yang bermutu/lolos uji material.

c) Pada saat pembuatan benda uji boleh ditambahkan dengan bahan addmixture yang dapat meningkatkan kekuatan beton, berdasarkan tujuan yang hendak dicapai.

d) Rentang waktu proses pencampuran bahan benda uji hingga pembuatan benda uji jadi dalam cetakan, tidak boleh melebihi 40 menit karena telah melampaui proses setting time.

e) Pada saat menuangkan beton segar ke dalam cetakan tidak boleh terjadi segregasi dan harus merata agar beton yang dihasilkan dalam satu varian tidak berbeda jauh satu sama lain.

f) Proses perawatan beton harus diperhatikan agar beton tidak rusak sebelum diuji.

\section{DAFTAR PUSTAKA}

ASTM International. 1997. Standard Test Method For Clay Lumps And Friable Particles In Aggregates ( ASTM C 142). United State : ASTM International.

ASTM International. 2004. Standard Specification For Chemical Admixtures For Concrete (ASTM C 494/C 494 M). United State : ASTM International.

Badan Standardisasi Nasional. 1989. SK SNI S-04-1989-F Spesifikasi Bahan Bangunan Bagian A (Bahan Bangunan Bukan Logam). Jakarta : Badan Standardisasi Nasional.

Badan Standardisasi Nasional. 1990. SNI 03-1968-1990 Metode Pengujian Tentang Analisis Saringan Agregat Halus Dan Kasar. Jakarta : Badan Standardisasi Nasional.

Badan Standardisasi Nasional. 1990. SNI 03-1971-1990 Metode Pengujian 
Kadar Air Agregat. Jakarta : Badan Standardisasi Nasional.

Badan Standardisasi Nasional. 1991. SNI 03-2495-1991 Spesifikasi Bahan Tambahan Untuk Beton. Jakarta : Badan Standardisasi Nasional.

Badan Standardisasi Nasional. 1991. SNI 15-2531-1991 Metode Pengujian Berat Jenis Semen Portland. Jakarta : Badan Standardisasi Nasional.

Badan Standardisasi Nasional. 1998. SNI 03-4804-1998 Metode Pengujian Bobot Isi Dan Rongga Udara Dalam Agregat. Jakarta : Badan Standardisasi Nasional.

Badan Standardisasi Nasional. 2002. SNI 03-6827-2002 Metode Pengujian Waktu Ikat Awal Semen Portland Dengan Menggunakan Alat Vicat Untuk Pekerjaan Sipil. Jakarta : Badan Standardisasi Nasional.

Badan Standardisasi Nasional. 2004. SNI 15-2049-2004 Semen Portland. Jakarta : Badan Standardisasi Nasional.

Badan Standardisasi Nasional. 2008. SNI 1969:2008 Cara Uji Berat Jenis Dan Penyerapan Air Agregat Kasar. Jakarta : Badan Standardisasi Nasional.

Badan Standardisasi Nasional. 2008. SNI 1970:2008 Cara Uji Berat Jenis Dan Penyerapan Air Agregat Halus. Jakarta : Badan Standardisasi Nasional.

Badan Standardisasi Nasional. 2008. SNI 1972:2008 Cara Uji Slump Beton. Jakarta : Badan Standardisasi Nasional.

Badan Standardisasi Nasional. 2008. SNI 2417:2008 Cara Uji Keausan Agregat Dengan Mesin Abrasi Los Angeles. Jakarta : Badan Standardisasi Nasional.

Badan Standardisasi Nasional. 2011. SNI 1974:2011 Cara Uji Kuat Tekan Beton dengan Benda Uji Silinder.
Jakarta : Badan Standardisasi Nasional.

Badan Standardisasi Nasional. 2012. SNI 7656:2012 Tata Cara Pemilihan Campuran Untuk Beton Normal, Beton Berat Dan Beton Massa. Jakarta : Badan Standardisasi Nasional.

Badan Standardisasi Nasional. 2013. SNI 2846:2013 Persyaratan Beton Struktural Untuk Bangunan Gedung. Jakarta : Badan Standardisasi Nasional.

Badan Standardisasi Nasional. 2014. SNI 2460:2014 Spesifikasi Abu Terbang Batubara dan Pozolan Alam Mentah atau yang Telah Dikalsinasi untuk Digunakan dalam Beton. Jakarta : Badan Standardisasi Nasional.

Badan Standardisasi Nasional. 2014. SNI 2816:2014 Metode Uji Bahan Organik Dalam Agregat Halus Untuk Beton. Jakarta : Badan Standardisasi Nasional.

Ervianto, Moch., Saleh, Fadillawaty., dan Prayuda, Hakas. 2006. Kuat Tekan Beton Mutu Tinggi Menggunakan Bahan Tambah Abu Terbang (Fly Ash) Dan Zat Adiktif (Bestmittel). Vol.20, No.3.

Julharmito., Fadli, Ahmad., dan Drastinawati. (2015): Pemanfaatan Limbah Abu Terbang (Fly Ash) Batu Bara Sebagai Bahan Campuran Beton Geopolimer, 2, 1-7.

Mulyono, T. Teknologi Beton. Yogyakarta: Andi. 2004.

Munir, Misbachul. (2008). Pemanfaatan Abu Batubara (Fly Ash) Untuk Hollow Block Yang Bermutu Dan Aman Bagi Lingkungan, Tesis Program Magister Ilmu Lingkungan, Universitas Diponegoro Semarang.

Wikana, Iwan dan Wantutrianus (2014): Pengaruh Pemakaian Fly Ash dan Abu Batu sebagai Pengganti Sebagian Semen pada Kuat Tekan Beton Mutu Tinggi, 1, 51. 